\title{
Cognitive rehabilitation of the updating sub-component of working memory in schizophrenia: A case study
}

\author{
M-N. Levaux ${ }^{1,2}$, J. Vezzaro ${ }^{1}$, F. Larøi ${ }^{1}$, I. Offerlin-Meyer ${ }^{2}$, J-M. Danion², and M. Van der Linden ${ }^{1,3}$ \\ ${ }^{I}$ Cognitive Psychopathology Unit, University of Liège, Belgium; ${ }^{2}$ Psychiatry Service I, Inserm 666 Unit, Strasbourg, France; ${ }^{3}$ Cognitive \\ Psychopathology and Neuropsychology Unit, University of Geneva, Switzerland
}

\begin{abstract}
Working memory problems have been identified as a core cognitive deficit in schizophrenia. In this paper, we present the results of a cognitive rehabilitation programme (Duval \& Coyette, 2005) administered to a schizophrenia patient, and specifically designed to improve the updating sub-component of working memory. The original feature of this programme was that it involved two types of updating exercises: cognitive and ecological. The purpose was to enable the patient to acquire cognitive strategies that alleviate the mental load of the central executive and to transfer them to daily life. The specificity and efficacy of the programme were assessed with multiple (cognitive, ecological and non-target) baseline measurements. In addition, several questionnaires were administered to assess the effect of the programme on subjective cognitive complaints affecting daily life, psychiatric symptoms and self-esteem. The results demonstrated the efficacy of the rehabilitation programme on the updating function and the generalisation of these beneficial effects to daily life. A significant decrease in both subjective cognitive complaints and psychiatric symptoms was also observed. However, the patient's self-esteem did not improve.
\end{abstract}

Keywords : Working memory ; Updating; Schizophrenia ; Cognitive rehabilitation ; Everyday activities.

The authors would like to thank YN for his participation. We would also like to thank Julie Duval and Françoise Coyette for allowing us to use their cognitive rehabilitation programme. Finally, we are indebted to Dr. H. Mourad for his assistance in symptom ratings and to asbl Réflexions for help with patient recruitment. This study was supported by a grant from an Interreg IIIB project and from a MiRe-DRESS project.

\section{INTRODUCTION}

Working memory is a capacity-limited system responsible for the temporary storage and processing of information relevant to ongoing mental operations (Baddeley, 1992, 2000). The most widely used model of working memory (Baddeley, 1986) describes two slave sub-systems, the phonological loop and the visuospatial sketchpad, which temporarily maintain verbal and visuospatial information, respectively. These two slave subsystems are under the control of a central executive component. The latter is an attentional control system responsible for the control and coordination of the various processes involved in short-term memory, information transfer from short-term memory to long-term memory, and efficient strategy selection. Furthermore, the central executive may also be divided into a number of executive sub-processes (Baddeley \& Wilson, 2002), such as coordination of two simultaneous tasks, selective attention, and manipulation of information within long-term memory. Miyake et al. (2000) have examined the organisation of three of the most frequently postulated central executive functions in the literature: updating of working memory representations, shifting of mental sets or tasks, and inhibition of prepotent responses. They showed that these sub-processes shared some underlying commonality but were clearly independent, thus indicating that executive functions are both diverse and unitary.

Many studies have revealed working memory deficits in schizophrenia patients. A recent meta-analysis (Lee \& Park, 2005) revealed a positive effect size of 0.45 for working memory impairment in schizophrenia patients as compared to controls (according to Cohen, 1988, this is a moderate effect size). Furthermore, there were no significant differences in working memory deficits when visuospatial and verbal modalities were compared. In addition, working memory deficits did not appear to be an artifact of particular task parameters, such as the duration of the delay interval. Finally, working memory deficits have been reported in several studies (e.g., Barch et al., 2001; Carter et al., 1996; Daban et al., 2005) that included non-medicated schizophrenia patients, suggesting that such deficits cannot be primarily related to medication.

Working memory deficits have also been documented in first-degree family members of schizophrenia patients (Conklin, Curtis, Katsanis, \& Iacono, 2000; Myles-Worsley \& Park, 2002; Park, Holzman, \& Lenzenweger, 1995), in schizotypal persons, and in individuals with schizotypal personality disorder (Mitropoulou et al., 2005; Park et al., 1995; Park \& McTigue, 1997; Tallent \& Gooding, 1999). These studies suggest that working memory deficits may be considered a schizophrenia neurocognitive endophenotype (see also, Gur et al., 2007), 
that is, a factor present before the manifestation of the illness.

Deficits in working memory may underlie other cognitive deficits in schizophrenia. In particular, Silver, Feldman, Bilker, and Gur (2003) have shown that verbal working memory is specifically linked to executive functions and visuomotor coordination, while spatial working memory is significantly correlated with long-term memory for objects and faces. Visual retention memory for designs, visual orientation, and simple motor function depend upon both spatial and verbal working memory capacities. According to Silver et al. (2003), these results suggest that working memory deficits represent core symptoms of the cognitive impairment in schizophrenia. Other functions have also been related to working memory in schizophrenia, such as language comprehension (Bagner, Melinder, \& Barch, 2003) and sustained attention (Silver \& Feldman, 2005).

Because of the central role of working memory, its impairment causes various problems in daily life, such as difficulty following conversations, the thread of a movie or a book, and difficulty carrying out two tasks simultaneously. Indeed, several reviews of the literature have reported a clear link between working memory deficits and social functioning/quality of life in schizophrenia (Green, 1996; Green, Kern, Braff, \& Mintz, 2000). Green et al. (2000) examined the degree to which cognitive deficits could predict the functioning of schizophrenia patients in their everyday life. In particular, they showed that five out seven studies reported a positive relation between "immediate memory" and the acquisition of psychosocial skills. It is important to note, however, that the immediate memory domain primarily included measures requiring only brief storage of information and not the ability to manipulate that information. In a more recent study, Takahashi et al. (2005) observed that spatial working memory deficits were significantly correlated with a number of aspects of social functioning: self-care skills (e.g., table manners, washing, care of possessions), speech disturbance (sense and clarity), and community skills (use of money and community facilities). Alptekin et al. (2005) found a relationship between perceived quality of life and working memory in a group of schizophrenia patients. In particular, patients' performance on a digit span test correlated significantly with scores in the social relationship domain (personal relationships, social support, and sexual activity) of the World Health Organization Quality of Life - Brief Form. Perceived quality of life was not influenced by the severity of disease or by drug side effects. Finally, Hofer et al. (2005) reported a significant correlation between performance on a working memory task and schizophrenia patients' employment status (full-time employment, part-time employment, supported employment or unemployed). Thus, in general, these findings suggest that working memory deficits are associated with the functional status of schizophrenia patients.

Cognitive rehabilitation improves cognitive deficits in a number of domains in schizophrenia patients, including working memory functioning. A recent meta-analysis (McGurk, Twamley, Sitzer, McHugo, \& Mueser, 2007) has shown that cognitive rehabilitation (including different types of cognitive programmes, such as drill and practice, and strategy coaching) in schizophrenia patients has a beneficial effect on overall cognition (effect size for overall cognition: 0.41 ) and specifically a medium effect size of 0.52 was found for verbal working memory. McGurk et al. (2007) furthermore note that the effect sizes on cognitive functioning have not appeared to have increased appreciably in recent years, and they propose a number of reasons as to why this is the case. We believe that this state of affairs is due to a number of theoretical and methodological issues that have not been taken into account in previous approaches to cognitive rehabilitation in schizophrenia patients. First, the cognitive programmes used in the cognitive rehabilitation studies are not specific to one cognitive function but rather aim to improve several cognitive domains (e.g., attention, working memory, episodic memory). Consequently, it is not possible to evaluate the specific treatment effect that the programme had on a given cognitive function and, in particular, the specific role that each function may have played in improving schizophrenia patients' cognitive and social functioning. Second, some of these studies did not take into account the heterogeneity of cognitive deficits characterised in schizophrenia (e.g., Goldstein \& Shemansky, 1995; Joyce, Hutton, Mutsatsa, \& Barnes, 2005; Joyce \& Roiser, 2007; Seaton, Goldstein, \& Allan, 2001), as the same cognitive rehabilitation programme was administered to all the patients. For instance, in the case of working memory, two schizophrenia patients could show a completely different pattern of impairment, i.e., affecting differently the slave systems (phonological loop and visuospatial sketchpad) and/or the sub-processes of the central executive such as information manipulation, updating, and dual-task monitoring. Third, and perhaps most importantly, difficulties in patients' everyday lives have not been given the importance they deserve when designing and proposing cognitive rehabilitation programmes. These everyday difficulties are furthermore clearly heterogeneous and therefore will vary tremendously from patient to patient. Indeed, according to the World Health Organization's (1980) distinction between impairment (dysfunction of a particular system), disability (results of this impairment on activities), and handicap (barrier to fulfilling personal and social roles created by this impairment or disability), cognitive rehabilitation should in this context (in addition to remediating impaired cognitive domains) ultimately focus on disability and handicap levels (psychosocial functioning). So, in addition to accurately identifying the impaired cognitive domains and preserved capacities in a schizophrenia patient, it is equally important (if not more important) to define the consequences of the cognitive deficits for daily life activities and to develop ecological strategies based on concrete objectives in 
daily life. Consequently, the efficacy of a cognitive rehabilitation programme should be based not only on the results of cognitive tests and baselines, but also on ecological baselines, subjective cognitive complaints questionnaires and other everyday life measures. One way of taking this heterogeneity into account in schizophrenia patients (i.e., both cognitive heterogeneity and heterogeneity in terms of everyday life difficulties and needs) is to adopt a case study or multiple case study approach (Shallice, Burgess, \& Frith, 1991).

Therefore, the goal of the present case study was to examine the specific impact that a cognitive rehabilitation programme for working memory deficits would have on a schizophrenia patient in terms of cognitive functioning, everyday functioning, psychiatric symptoms, and self-esteem. More specifically, the cognitive rehabilitation programme used in the present study (Duval \& Coyette, 2005) focused on the rehabilitation of one target sub-component of the central executive, namely the "updating" function. This sub-component was specifically impaired in the patient and the deficit was associated with certain daily life problems. Many studies have emphasised a specific impairment in the ability to update working memory, particularly with the $n$-back task, in first-episode schizophrenia patients (e.g., Chan, Chen, \& Law, 2006; Krieger, Lis, Cetin, Gallhofer, \& Meyer-Lindenberg, 2005) and in chronic patients (e.g., Callicott et al., 2000; Carter et al., 1998; Goldberg et al., 2003; Perlstein, Dixit, Carter, Noll, \& Cohen, 2003). This deficit is associated with poverty of engagement with the environment (Galletly, MacFarlane, \& Clark, 2007). The original feature of the cognitive rehabilitation programme utilised in this study is the fact that cognitive exercises are accompanied by ecological exercises: the patient first learned to acquire cognitive strategies to alleviate the mental load of the central executive, and then learned how these strategies could be applied in daily life. The specificity and efficacy of the programme were measured with multiple (cognitive, ecological, and non-target) baseline measurements. In addition, several questionnaires were administered to assess the effect of the programme on subjective cognitive complaints in daily life, psychiatric symptoms and self-esteem.

\section{CASE REPORT}

YN is a right-handed 29-year-old man, who is unmarried and lives with his parents. He completed his primary education without problems, but had difficulties completing his secondary studies, as he repeated a year twice.

He then finished secondary school in a technical commercial option. After that, he went on to post-secondary studies, which he stopped in the second year due to stress. It was during this period (at 20-21 years of age) that he was first diagnosed with paranoid schizophrenia according to DSM-IV criteria (American Psychiatric Association, 1994). He was hospitalised four times, the last time in January 2005 (approximately one year before the cognitive rehabilitation). YN is not formally employed, but occasionally carries out accountancy tasks in his father's firm. Socially, YN has few close friends, and his psychiatric symptoms are dominated by social withdrawal, apathy, feelings of guilt, anxiety and depression. At the time of the study, his medication consisted of an atypical neuroleptic (olanzapine: $2 \times 10 \mathrm{mg}$ ) and one benzodiazepine (lorazepam: $3 \times 2.5 \mathrm{mg}$ ).

YN described a number of cognitive complaints in everyday life: difficulties concentrating when watching television, listening to the radio, reading a book, or learning guitar scores. He also reported that during conversations he had difficulty understanding successions of themes, or their development. In his workplace (accounting), he mentioned difficulties remembering numbers that had to be encoded and therefore had to frequently verify the numbers before they were encoded.

\section{Pre-rehabilitation cognitive assessment}

An extensive neuropsychological battery was administered to YN. The examination covered working memory (storage, processing load, updating, and dual-task monitoring), episodic memory (verbal and visual), procedural memory, attentional functions (divided attention, sustained attention, and vigilance), executive functions (inhibition, flexibility, and planning), processing speed, language, and general cognitive functioning (see Table 1).

The results were calculated on the basis of Z-scores or percentiles and are presented in Table 1. A score indicating a deficit was set at less than -1.65 for the Z-score and at less than 10 for the percentile score. Regarding YN's working memory performance, storage, processing load and dual-task monitoring were all preserved, except for updating, which was significantly impaired. Performance was significantly impaired on the verbal episodic memory test, but not the visual episodic memory and procedural memory tests. Analysis of executive functions showed deficits related to planning, but not to inhibition, flexibility or problem solving. YN's performance in language and attentional functions was preserved. His performance on the French adaptation of the National Adult Reading Test (fNART; Nelson, 1982; French adaptation, Mackinnon \& Mulligan, 2005) revealed normal pre-morbid estimated total IQ (113), verbal IQ (116) and performance IQ (108). 


\begin{tabular}{|c|c|c|}
\hline Tests & $\begin{array}{c}\text { Pre-rehabilitation } \\
\text { (Z-score / Percentile) }\end{array}$ & $\begin{array}{l}\text { Post-rehabilitation } \\
\text { (Z-score / Percentile) }\end{array}$ \\
\hline \multicolumn{3}{|l|}{ WORKING MEMORY } \\
\hline \multicolumn{3}{|l|}{ Storage } \\
\hline Digit span (forward) (MEM-III; Wechsler, 2001) & 0.28 & -0.62 \\
\hline \multicolumn{3}{|l|}{ Processing load } \\
\hline Digit span (backward) (MEM-III) & -0.78 & -0.13 \\
\hline Letter-number sequencing (MEM-III) & -0.33 & 0.33 \\
\hline \multicolumn{3}{|l|}{ Alpha Span (Belleville, Rouleau, \& Caza, 1998) } \\
\hline Serial order/Alphabetical order/Diminution rating & $0.05 /-1.12 /-1.19$ & $1 / 0.32 /-0.03$ \\
\hline \multicolumn{3}{|l|}{ Dual-task monitoring } \\
\hline \multicolumn{3}{|l|}{$\begin{array}{l}\text { Brown-Peterson (Meulemans, Coyette, \& Van der Linden, } \\
\text { in preparation) }\end{array}$} \\
\hline Interval $0 \mathrm{sec} / 5 \mathrm{sec} / 10 \mathrm{sec} / 20 \mathrm{sec}$ & $0.32 /-0.87 /-1.2 /-0.61$ & $0.32 /-0.38 /-1.6 /-0.61$ \\
\hline \multicolumn{3}{|l|}{ Updating } \\
\hline \multicolumn{3}{|l|}{ Working memory (TAP; Zimmerman \& Fimm, 1994) } \\
\hline Median RT/SD RT/Omission(s)/Error(s) & $\mathbf{P 7 / P 5 / P}>82 / \mathrm{P} 4$ & $\mathrm{P} 16 / \mathrm{P} 27 / \mathrm{P}>82 / \mathrm{P} 62$ \\
\hline \multicolumn{3}{|l|}{ MEMORY } \\
\hline \multicolumn{3}{|l|}{ Long-term verbal episodic memory } \\
\hline \multicolumn{3}{|l|}{ Logical memory (MEM-III) } \\
\hline I. First recall/Total recall/Learning curve/Theme & $1.33 /-\mathbf{1 . 6 7 / - 1 / - 1 . 6 7}$ & / \\
\hline II. Total recall/Retention \%/Theme & $-2 /-1.67 /-2$ & / \\
\hline \multicolumn{3}{|l|}{ Selective Reminding Test (Van der Linden et al., 2004) } \\
\hline Mean recall/10 trials/List learning \% / Delayed recall & / & $-5.03 /-4.64 /-13.89$ \\
\hline \multicolumn{3}{|l|}{ Long-term visual episodic memory } \\
\hline Face recognition (MEM-III): Part I/Part II/Retention & $0 / 0 / 0.67$ & / \\
\hline \multicolumn{3}{|l|}{ Procedural memory } \\
\hline \multicolumn{3}{|l|}{ Mirror Tracing (Marsh, Alexander, Packard, Zhu, \& } \\
\hline \multicolumn{3}{|l|}{ Peterson, 2005) } \\
\hline Trial 1: Time (sec)/Error(s)/Trial 10: Time (sec)/Error(s) & $\mathbf{- 3 . 6 8} / 0.78 /-0.05 / 0.63$ & / \\
\hline \multicolumn{3}{|l|}{ LANGUAGE } \\
\hline Verbal fluency: Phonological/Semantic & $-0.22 /-1.56$ & $2.18 /-0.4$ \\
\hline \multicolumn{3}{|l|}{ ATTENTIONAL FUNCTIONS } \\
\hline \multicolumn{3}{|l|}{ Divided attention } \\
\hline \multicolumn{3}{|l|}{$\mathrm{RT} / \mathrm{Omission}(\mathrm{s})$} \\
\hline \multicolumn{3}{|l|}{ Sustained attention } \\
\hline \multicolumn{3}{|l|}{$\begin{array}{l}\text { Continuous Performance Test - Identical Pairs (CPT-IP; } \\
\text { Cornblatt, et al, 1988) }\end{array}$} \\
\hline $\begin{array}{l}2 \text { numbers: Median RT (ms)/SD RT/Correct } \\
\text { resp./Error(s) }\end{array}$ & $-1.71 /-0.92 / 0.31 / 0.59$ & $-1.3 /-0.84 / 0.31 / 0.59$ \\
\hline $\begin{array}{l}3 \text { numbers: Median RT (ms)/SD RT/Correct } \\
\text { resp./Error(s) }\end{array}$ & $1.14 / 0.65 / 0.86 / 0.22$ & $0.65 / 0.71 / 0.86 / 0.97$ \\
\hline $\begin{array}{l}4 \text { numbers: Median RT (ms)/SD RT/Correct resp./ } \\
\text { Error(s) }\end{array}$ & $-0.3 /-0.26 / 1.03 / 0.19$ & $1.06 / 0.65 / 1.03 / 0.19$ \\
\hline \multicolumn{3}{|l|}{ Vigilance } \\
\hline $\begin{array}{l}\text { Vigilance (TAP): Median RT (ms)/SD RT/Correct } \\
\text { resp./Error(s) }\end{array}$ & $\mathrm{P} 54 / \mathrm{P} 50 / \mathrm{P} 31 / \mathrm{P} 54$ & / \\
\hline EXECUTIVE FUNCTIONS & & \\
\hline Inhibition & & \\
\hline Go/no-go (TAP): Median RT (ms)/SD RT/Error(s) & $\mathrm{P} 42 / \mathrm{P} 31 / \mathrm{P}>4$ & $\mathrm{P} 24 / \mathrm{P} 62 / \mathrm{P}>4$ \\
\hline Flexibility & & \\
\hline Trail Making Test (Reitan, 1958) & & \\
\hline Part A: Time (sec)/Error(s)/Part B: Time (sec)/Error(s) & $0.83 / 0.24 / 0.98 / 0.35$ & $1.51 / 0.24 / 1.35 / 0.35$ \\
\hline Digit Symbol - Coding (WAIS-IП; Wechsler, 2000) & -0.67 & -0.67 \\
\hline Flexibility (TAP): Median RT (ms)/SD RT/Error(s) & $\mathrm{P} 12 / \mathrm{P} 21 / \mathrm{P} 34$ & $\mathrm{P} 14 / \mathrm{P} 69 / \mathrm{P} 34$ \\
\hline Rule Shift Cards: Score (/4) /Temporal Judgement: Score & $0.43 /-0.42$ & $1 /$ \\
\hline
\end{tabular}

(/4) (BADS;

Wilson, Alderman, Burgess, Emslie, \& Evans, 1996) 


\section{Planning}

Six Elements Test (Shallice \& Burgess, 1991; French

adaptation,

Gamier et al,, 1998)

Total score (/1110)/Error(s)/Score BADS (/4)

Key Search: Score (/4) / Zoo Map: Score (/4) / Profile score (BADS)

Problem solving

Action Programme (BADS): Score (/4)

PROCESSING SPEED

Symbol Copy (WAIS-IП)

$-3.9 / 0.52 /-1.55$

$-0.63 /-1.26 / 0.6$

$-0.85 / 0.32 / /$

/

0.51

l

\%cum: 25-50

\%cum: 25-50

\section{TREATMENT STUDY}

\section{Duval and Coyette's (2005) rehabilitation programme}

Based on the results of YN's cognitive assessment and his subjective complaints, a cognitive rehabilitation programme focusing on the central executive was administered (Duval \& Coyette, 2005). This programme aims to improve three target central executive functions of working memory: processing load (storing and manipulating of information in working memory), updating (continuously modifying the contents of working memory based on newer incoming information) and dual-task monitoring (coordinating performance on two separate tasks). Two types of rehabilitation addressing these three functions separately were offered: cognitive and ecological. The former uses a variety of specific cognitive training tasks to target the central executive while the latter attempts to transfer this learning to everyday situations involving the central executive (scenarios analysis and simulations of real-life situations). The rationale of the programme is to teach patients to acquire three different reorganisation strategies that they have not previously used, or at least, have not used systematically (Seron \& Van der Linden, 2000): dual coding (verbal and visual), serial processing, and speed reduction (see below). The purpose underlying these strategies is to consolidate the encoding stages before proceeding to the processing of information, and to reduce the mental load of the central executive. The cognitive and ecological sub-programmes are organised into hierarchical levels of complexity, where progression is determined by the patient's responses (at least $80 \%$ correct responses at one level before moving on to the next). Verbal material (letters, non-words, and words) is used as it is easier to manipulate and is suitable for the use of reorganisation strategies (for more details, see Duval, Coyette, \& Seron, 2008).

\section{Application of the "updating" sub-programme}

Given that YN presented relatively specific updating problems, only the "updating" module (both the cognitive and ecological sub-programmes) of the programme was employed.

\section{Cognitive sub-programme}

Tasks and stimuli. The updating tasks consisted of " $n$-back" type exercises: while a continuous stream of stimuli was presented by the therapist (visually or orally; see Table 2 for more detail), YN had to tap on the table when the last stimulus presented was identical to a stimulus seen or heard $n$ stimuli back before the presentation of this last stimulus. This task requires that the patient maintain information in working memory and refresh some (but not all) of it as new information is presented.

TABLE 2 Cognitive sub-programme: Progression of exercises

\begin{tabular}{|c|c|c|c|}
\hline Level & $\begin{array}{c}\text { Modality of } \\
\text { presentation }\end{array}$ & Facilitation cues & Description \\
\hline 0 & & $\begin{array}{l}\text { Triple visual support: } 1 \text {. All } 2 \text { or } 3 \\
\text { windows open. } 2 \text {. Strip (movable). } \\
\text { 3. Written words (on the strip). }\end{array}$ & $\begin{array}{l}\text { Familiarisation with the spatial array of } \\
\text { windows (the words written on the strip } \\
\text { passes through the windows). }\end{array}$ \\
\hline 1 & $\begin{array}{l}\text { Visual } \\
\text { presentation of } \\
\text { words }\end{array}$ & $\begin{array}{l}\text { Triple visual support: } 1 \text {. Left } \\
\text { window(s) closed. } 2 \text {. Strip } \\
\text { (movable). } 3 \text {. Written words (on } \\
\text { the strip). }\end{array}$ & $\begin{array}{l}\text { The new stimulus (to be encoded) appears in } \\
\text { the right window and the old stimulus (to be } \\
\text { forgotten) disappears from the closed left } \\
\text { window. }\end{array}$ \\
\hline
\end{tabular}




\begin{tabular}{ccc}
\hline 2 & $\begin{array}{c}\text { Double visual support: 1. Left } \\
\text { window(s) closed. 2. Each word } \\
\text { written on a cardboard (removed } \\
\text { after the person has read it). }\end{array}$ & $\begin{array}{c}\text { The person has to imagine that the word is on } \\
\text { a strip sliding from the right to the left } \\
\text { window. }\end{array}$ \\
\hline 3 & $\begin{array}{c}\text { Single visual support: 1. Left } \\
\text { window(s) closed. }\end{array}$ & $\begin{array}{c}\text { The person has to mentally visualise (with } \\
\text { only the windows in front of him/her) words } \\
\text { on an imaginary strip }\end{array}$ \\
\hline $\begin{array}{c}\text { Auditory } \\
\text { presentation of } \\
\text { words }\end{array}$ & $\begin{array}{c}\text { Certain words are presented several times } \\
\text { without being n-back. Subsequently, 3-back } \\
\text { series are added (2 series of 2-back and } 4 \\
\text { series of 3-back). }\end{array}$
\end{tabular}

4

Mental support (i.e., no visual support).
Letters are presented orally.

Certain letters are presented orally several times without being n-back.

Moreover, 3-back series are added (2 series of 2-back and 4 series of 3-back).

The stimuli were words (concrete and visual di- or tri-syllables) and letters (10 consonants that are sufficiently phonologically distinct). The word pairs (1-back condition) or trios (2-back condition) to be retained temporarily in memory were not related semantically, visually or phonologically. Words were presented once serially (except for the $3+$ and $4+$ levels) and letters were presented the same number of times. Two series of 40 1-back stimuli and two series of 40 2-back stimuli were presented for each level of difficulty (see below) except for the initiation level (comprehension of instructions), which contained series of 10 stimuli.

Exercise progression. The programme comprised four different levels of difficulty that were constructed according to three different parameters (see Table 2): (1) modality of presentation, that is, first visual and then auditory; visual presentation is easier for the patient as it allows double encoding (visual and verbal) and the encoding is carried out at the patient's pace (the stimulus is visible for the required time, whereas during an auditory presentation, the patient must try to visualise the item as well); (2) type of stimuli: words and then letters; letters are more difficult to memorise than words (e.g., if the word apple is presented, then the patient sees not only the graphemic sequence $a-p-p-l-e$, he also hears the phonological sequence and sees the mental image of the apple; whereas if the letter $L$ is presented, he only sees the grapheme and hears the associated phoneme); and (3) the length of the $n$-back (first 1-back and then 2-back).

Moreover, in order to help the patient, a visual tool (spatial array of windows) was specifically constructed (see Figure 1). Three stages were also prepared in order to increase the complexity of the exercises (see Table 2). First, the stimuli to be processed were presented visually on a strip passing behind two (1-back condition) or three (2-back condition) windows. The updating process was visually simulated by the displacement of the stimuli; as a result, the new stimulus (to be encoded) appeared in the right window and the old stimulus (to be forgotten) disappeared from the left window. Second, the visual tool was progressively removed so that the stimuli were presented solely in the auditory modality. Finally, the patient learned how to perform the $n$-back task by mentally representing a flow of stimuli moving from right to left.

Figure 1. Example of visualisation tool for updating exercises (type 1-back) (Duval et al., 2008) (*"cat", "bowl", "foot", "wheel").

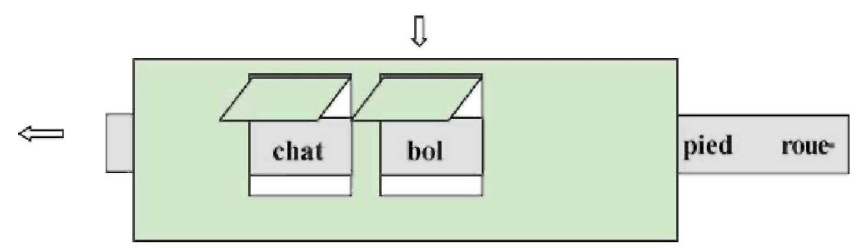

Rationale. At the beginning of each exercise, the patient learned to apply three different reorganisation 
strategies:

1. Dual coding strategy: Use of the two slave systems of working memory (phonological loop and visuospatial sketchpad) to allow richer encoding than with the phonological loop alone. Thus, when each stimulus in a sequence was presented, the patient had to repeat its name slowly and then was asked to visualise it (with the help of the visual tool).

2. Serial work strategy: Encoding of all the stimuli, and then processing them to avoid being confronted with dual-task situations. In this way, once the patient had encoded the presented stimulus (i.e., repeated and visualised), he repeated the stimuli that he was required to encode in memory.

3. Speed reduction strategy: Exercises were performed at the patient's pace or at a pace monitored by the therapist in order to avoid any tendency to impulsivity, which may result in superficial encoding or overly rapid repetition.

The therapist gave YN feedback about his performance. In case of an error, the therapist and the patient tried to understand its origin and, if necessary, the strategies were explained again.

\section{Ecological sub-programme}

Tasks and stimuli. The ecological rehabilitation followed the cognitive rehabilitation in three successive phases:

1. Information session: In this phase, the therapist explained the variables that can negatively influence cognitive performance in daily life (e.g., stress, anxiety, dual-task situations, etc.) and provided various optimisation strategies (e.g., minimise internal interference, use the dual coding strategy, etc.) for working memory with everyday examples.

2. "Scenarios analysis": This phase helped the patient to become aware of the role of the central executive in real life and to identify everyday situations where the strategies could be helpful. To begin with, the patient was given a short text describing a real-life problem involving working memory (setting). The patient was then asked to apply the most efficient and least taxing solution in considering the advantages and disadvantages of the various strategies (analysis). Finally, the therapist provided feedback and there was a discussion. The patient was then invited to present scenarios that he encountered in his daily life and which had caused difficulty because they involved working memory. The same stages (setting, analysis, and discussion) were applied. The scenarios were evaluated qualitatively and quantitatively, and one point was awarded for each strategy mentioned (i.e., repetition, mental visualisation, and updating).

3. "Simulations of real-life situations": This phase aimed to promote the application of strategies to daily life, that is, in addition to analysing the situation, the patient had to select strategies and perform any related actions. This involved the following stages. First, the patient was given a short text describing a daily life situation that required working memory intervention (setting) (e.g., looking for books in a library). Next, the patient had to search mentally for the most efficient and least taxing solution (analysis). The therapist then provided detailed information (instructions) (e.g., the titles of the books) and the patient was asked to carry out the exercise (action). Finally, the therapist gave the patient feedback and a debriefing took place for any difficulties that were encountered (discussion). The evaluation of the simulations of real-life situations was quantitative (one point for each correct response) and qualitative.

The ecological updating exercises (scenarios analysis and simulations of real-life situations) consisted of 1-back tasks and followed the same progression as the cognitive exercises: visual and then auditory presentation of stimuli. Moreover, at first these exercises only involved the updating function, but then this function was integrated with another one (processing load or dual-task monitoring) (see Table 3).

TABLE 3 Ecological sub-programme: Progression of exercises

Type of ecological exercises Sub-component of working memory $\quad$ Type of presentation

\begin{tabular}{lcc}
\hline Scenarios analysis & Updating & Visual presentation (1 exercise) \\
\cline { 2 - 3 } & & Auditory presentation (1 exercise) \\
\cline { 2 - 3 } Simulations of real-life situations & Updating and processing load & Visual presentation (1 exercise) \\
\cline { 2 - 3 } & Updating & Visual presentation (1 exercise) \\
\cline { 2 - 3 } & & Auditory presentation (1 exercise) \\
\cline { 2 - 3 } & Updating and processing load & Visual presentation (3 exercises) \\
\hline
\end{tabular}




\section{Treatment design}

The rehabilitation consisted of two 90-minute sessions per week and lasted three months. In total, the rehabilitation consisted of 20 sessions (for the order of sessions, see Table 4). Before starting the cognitive rehabilitation programme, there was an information session which consisted of presenting YN's results from the cognitive assessment; interpreting his cognitive deficits; and explaining the general role of working memory and its functioning, the consequences of an impairment of this system and the plan for the rehabilitation programme.

The intervention plan was designed to evaluate the effect of the cognitive rehabilitation sub-programme, the ecological rehabilitation sub-programme, and the rehabilitation programme in its entirety. For this purpose, assessment was carried out with multiple baseline measurements and several questionnaires at three different times: (1) pre-rehabilitation, (2) between the cognitive and ecological sub-programmes (intermediate), and (3) post-rehabilitation. Moreover, in order to determine whether changes resulted from the treatment of other cognitive functions, the neuropsychological evaluation was carried out before and after the rehabilitation programme.

\section{Baseline measurements}

Three types of complementary baseline measurements (cognitive, ecological, and non-target) were administered. For each type, seven parallel versions of the tests were constructed in order to minimise test-retest effects: three were administered pre-rehabilitation, two at the intermediate point and two post-rehabilitation (see Table 4).

To evaluate the specific effect of the cognitive rehabilitation sub-programme, cognitive baselines were constructed for two tasks:

1. 3-back letters: This task was based on those included in Duval et al. (2008) and consisted of 16 series of letters (between 5 and 8 letters) presented one by one on a computer screen (1 per second). At the end of each series, an $\mathrm{X}$ appeared and the patient was required to name the second-last letter (one point was given for each correct letter for each series; maximum score $=16$ ). The 3-back task was used to avoid ceiling effects obtained with the 2-back task.

2. Size judgement: This task was based on Palladino, Cornoldi, De Beni. and Pazzaglia (2001) and consisted of five series of 12 words ( 7 abstract words and 5 words belonging to a semantic category - object or animal). The series of words was read to the patient and, at the end of each series, the patient had to recall the three shortest items belonging to the semantic category (one point was given for each correct item for each series; maximum score $=15$ ). The words in the different lists did not differ according to the number of letters, emotional valence, degree of imagery, or frequency, MANOVA, $F(3,18)=1.4 ; p=.12$.

To evaluate the specific effect of the ecological rehabilitation sub-programme, ecological baselines were constructed comprising two evaluation sets:

1. Scenarios analysis: The examiner read a short text describing a situation (e.g., choose the least expensive product in a supermarket), and the patient had to find the most efficient strategy to retain the information (this strategy was described in detail to the examiner). One point was awarded for each appropriate strategy given (i.e., repetition, mental visualisation, and updating; maximum score $=3$ ).

2. Simulations of real-life situations: The examiner read a short text with general information about a situation (e.g., train timetable: "Listen to the train timetable for all the next destinations and remember the departure time, arrival time and platform of the train that will allow you to arrive earliest in a given city."). Then the examiner provided the information (e.g., timetables of all trains) and the patient had to respond. One point was awarded for each correct response made in each situation (maximum score $=9$ ). The scenarios and the simulations of reallife situations used for the baselines were never presented to the patient during the treatment process.

In order to test the effect of the rehabilitation programme on an impaired cognitive function (i.e., verbal episodic memory) that was not rehabilitated, non-target baselines were introduced. The verbal episodic memory task consisted of learning and recalling (5 trials) 15 non-semantically related words. A delayed recall task was administered after 20 minutes. The words contained in the different lists did not differ in terms of the number of letters, emotional valence, degree of imagery or frequency, MANOVA, $F(4,24)=0.94 ; p=.60$.

TABLE 4 Type, order, and number of sessions

\begin{tabular}{|c|c|}
\hline Session type & $\begin{array}{c}\text { No. of } \\
\text { sessions }\end{array}$ \\
\hline Pre-rehabilitation cognitive assessment & 1 \\
\hline Information session & 1 \\
\hline Pre-rehabilitation measurements (baseline measurements and questionnaires) & 3 \\
\hline Cognitive rehabilitation & 6 \\
\hline
\end{tabular}


Intermediate rehabilitation measurements (baseline measurements and

questionnaires)

Ecological rehabilitation

\section{Questionnaires}

A number of self-assessment questionnaires were administered to evaluate the effects of the cognitive rehabilitation on cognitive functioning in daily life and self-esteem:

1. The Questionnaire d'Auto-évaluation de la Mémoire (Memory Self-Assessment) (QAM; Van der Linden, Wyns, Coyette, von Frenckell, \& Seron, 1989). The QAM consists of 48 questions that assess memory functioning (episodic, prospective, semantic, procedural, and working memory) in various daily activities. For each question, the patient had to indicate the frequency of his difficulties on a 6-point Likert scale ranging from "never" (score 1) to "always" (score 6). YN's mother also completed this questionnaire. The total score ranges between 48 and 288 .

2. The Questionnaire d'Auto-évaluation de l'Attention (Attention Self-Assessment) (QAA; Coyette et al., 1999). The QAA consists of 59 questions that assess different aspects of attention (processing speed, tonic alertness, focused attention, divided attention, vigilance, attentional slips, and questions about working memory quality) in everyday situations. YN had to answer on the same 6-point Likert scale as for the QAM. His mother also completed this questionnaire. The total score ranges between 59 and 354 .

3. The Questionnaire d'Auto-évaluation de la Mémoire de Travail (Working Memory Self-Assessment) (QAMT; Hiernaux \& Demoulin, 1999) The QAMT contains 20 questions that investigate difficulties encountered in two main domains (simultaneous information storage and processing, and dual-task monitoring). Again, 6-point Likert scales are used. The total score ranges between 20 and 100.

4. The Subjective Scale to Investigate Cognition in Schizophrenia (SSTICS; Stip, Caron, Renaud, Pampoulova, \& Lecomte, 2003). The SSTICS was used to obtain an index of the patient's subjective cognitive complaints (memory, attention, executive function, and praxis). This scale consists of 21 questions, where the patient had to answer on a 5-point Likert scale ranging from "never" (score 0) to "very often" (score 4). The total score ranges between 0 and 84 .

5. The Self-esteem Inventory (SEI; Coopersmith, 1981; French adaptation, Coopersmith, 1984). The SEI consists of 50 items that are grouped into four domains (general, social, familial, and professional) to which the patient responds by indicating whether the sentences described him or not ("like me" or "unlike me"). The total score ranges between 0 and 50. A lie-scale was added to verify the honesty of the patient's responses but these results were not included in the total score. YN had a low score on this scale (3/8).

Finally, clinical symptoms before and after the cognitive rehabilitation were assessed using a French adaptation (Lépine, Piron, \& Chapatot, 1989) of the Positive and Negative Syndrome Scale (PANSS; Kay, Opler, \& Fiszbein, 1986) by an independent and experienced clinician.

\section{RESULTS}

\section{Post-rehabilitation cognitive assessment}

Post-rehabilitation results for the cognitive assessment are presented in Table 1. As a reminder, the results of the pre-rehabilitation cognitive assessment indicated deficits in updating, verbal episodic memory, and planning. The comparisons of the pre- and post-rehabilitation cognitive assessments revealed improved updating and planning functions. No improvement was observed for verbal episodic memory. Finally, processing load of working memory and flexibility, which were not impaired before the rehabilitation, also improved.

\section{Baseline measurements}

The results of the baseline measurements are presented in Figure 2.

\section{Pre-rehabilitation baselines}

YN's performance on the baseline measurements was stable across the three pre-rehabilitation assessments except that two significant decreases were observed between the second and third assessments for the 3-back and size judgement cognitive tasks. Furthermore, it should be noted that two pre-rehabilitation baselines were not included in the statistical analyses: the 2-back task, due to a ceiling effect at the first assessment (this was replaced by a 3-back task), and the simulations of real-life situations task at the second assessment, where YN 
obtained the maximum score. In particular, for the simulations of real-life situations task, YN's performance for the first and third pre-rehabilitation assessment was 1/9 (i.e., 11\% correct performance) and 2/9 (22\% correct performance), respectively. In contrast, his performance for this task on the second assessment was $9 / 9(100 \%$ correct performance). This surprising increase of performance could be interpreted on the basis of YN's statement: he expressly mentioned that he gave the only proposition that he had heard. Therefore, the maximum score on the simulations of real-life situations task could be attributed to chance.

Figure 2. Baseline measurements at different stages of the rehabilitation.
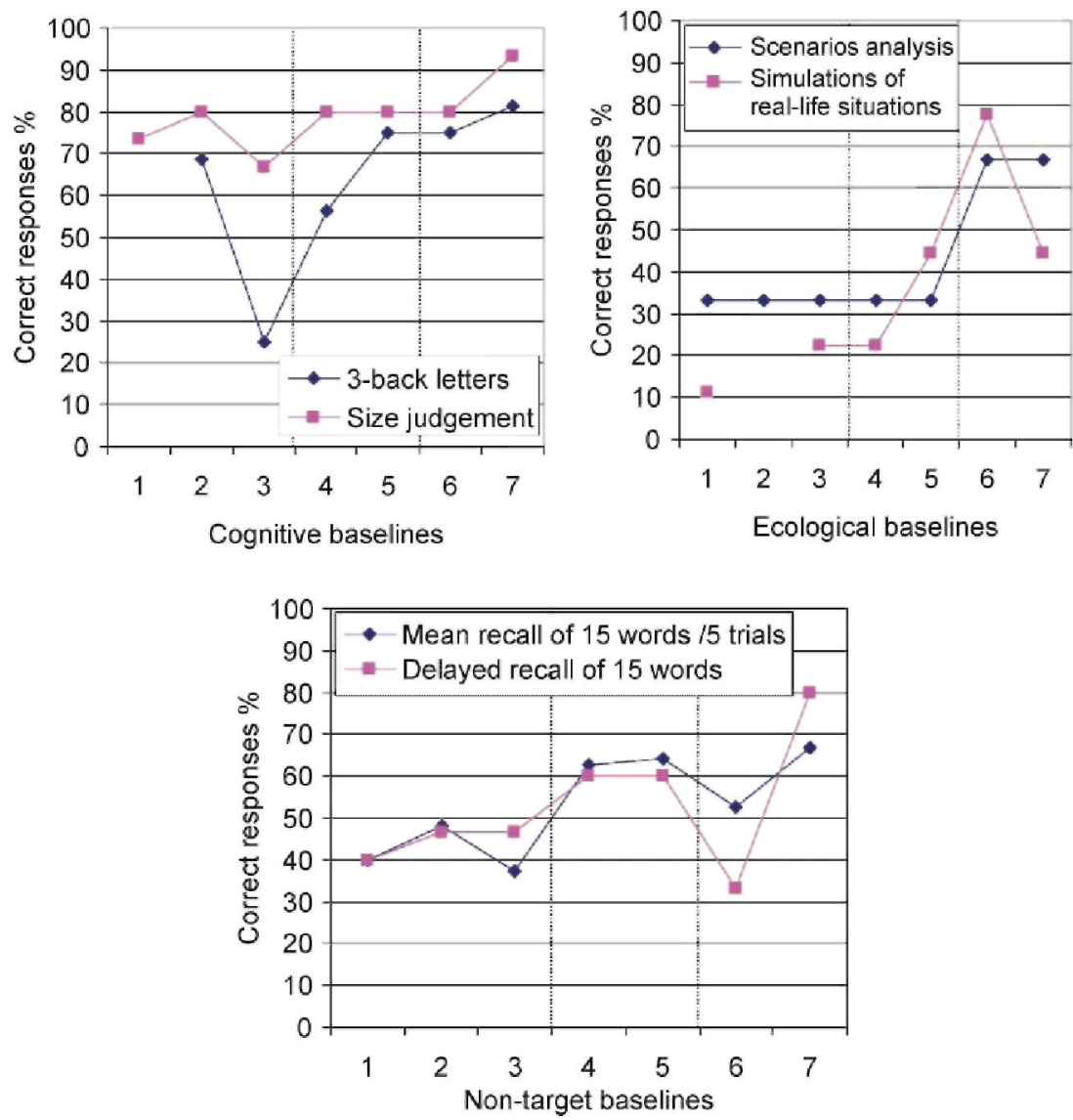

\section{Baseline measurements comparisons}

Three comparisons for the baseline measurements were carried out: (1) pre- versus intermediate rehabilitation (evaluating the effect of the cognitive sub-programme), (2) intermediate versus post-rehabilitation (evaluating the effect of the ecological sub-programme), and (3) pre- versus post-rehabilitation (evaluating the effect of the rehabilitation programme in its entirety).

To obtain a valid and reliable representation of scores on baseline tasks at the three assessment times (pre-, intermediate and post-rehabilitation), the mean scores (percentage of correct responses) were calculated. Statistical methods included chi-square tests to compare the pairs of mean scores.

Pre vs. intermediate comparisons. Cognitive baselines: significant improvement was noted for the 3-back task, $\chi^{2}(1)=8.33 ; p=.004$, but not for the size judgement task, $\chi^{2}(1)=1.36 ; p=.24$. Ecological baselines: significant improvement was observed for the simulations of real-life situations task, $\chi^{2}(1)=6.83 ; p=.009$, but not for the scenarios analysis task, $\chi^{2}(1)=0 ; p=.1$. Non-target baselines: significant improvement was observed for the mean recall of words over 5 trials, $\chi^{2}(1)=8.84 ; p<.003$, and for the total recall of words in the delayed recall condition, $\chi^{2}(1)=4.51 ; p=.03$.

Intermediate vs. post comparisons. Cognitive baselines: significant improvement was observed for the 3-back task, $\chi^{2}(1)=4.7 ; p=.03$, but not for the size judgement task, $\chi^{2}(1)=1.78 ; p=.18$. Ecological baselines: significant improvement was observed for both tasks: scenarios analysis, $\chi^{2}(1)=23.12 ; p<.001$, and simulations of real-life situations, $\chi^{2}(1)=15.74 ; p<.001$. Non-target baselines: no significant difference was observed for the mean recall of words over 5 trials, $\chi^{2}(1)=0.75 ; p=.39$, or for the total recall of words in 
delayed recall condition, $\chi^{2}(1)=0.19 ; p=.67$.

Pre vs. post comparisons. Cognitive baselines: significant improvement was observed for both tasks: 3-back, $\chi^{2}(1)=24.44 ; p<.001$, and size judgement, $\chi^{2}(1)=6.13 ; p=.01$. Ecological baselines: significant improvement was observed for both tasks: scenarios analysis, $\chi^{2}(1)=23.12 ; p<.001$, and simulations of real-life situations, $\chi^{2}(1)=40.69 ; p<.001$. Non-target baselines: there was a significant improvement for the mean recall of words over 5 trials, $\chi^{2}(1)=4.5 ; p=.03$, while the total recall of words in delayed recall condition showed a trend towards improvement, $\chi^{2}(1)=2.88 ; p=.09$.

TABLE 5 Results of questionnaires at different stages of the rehabilitation

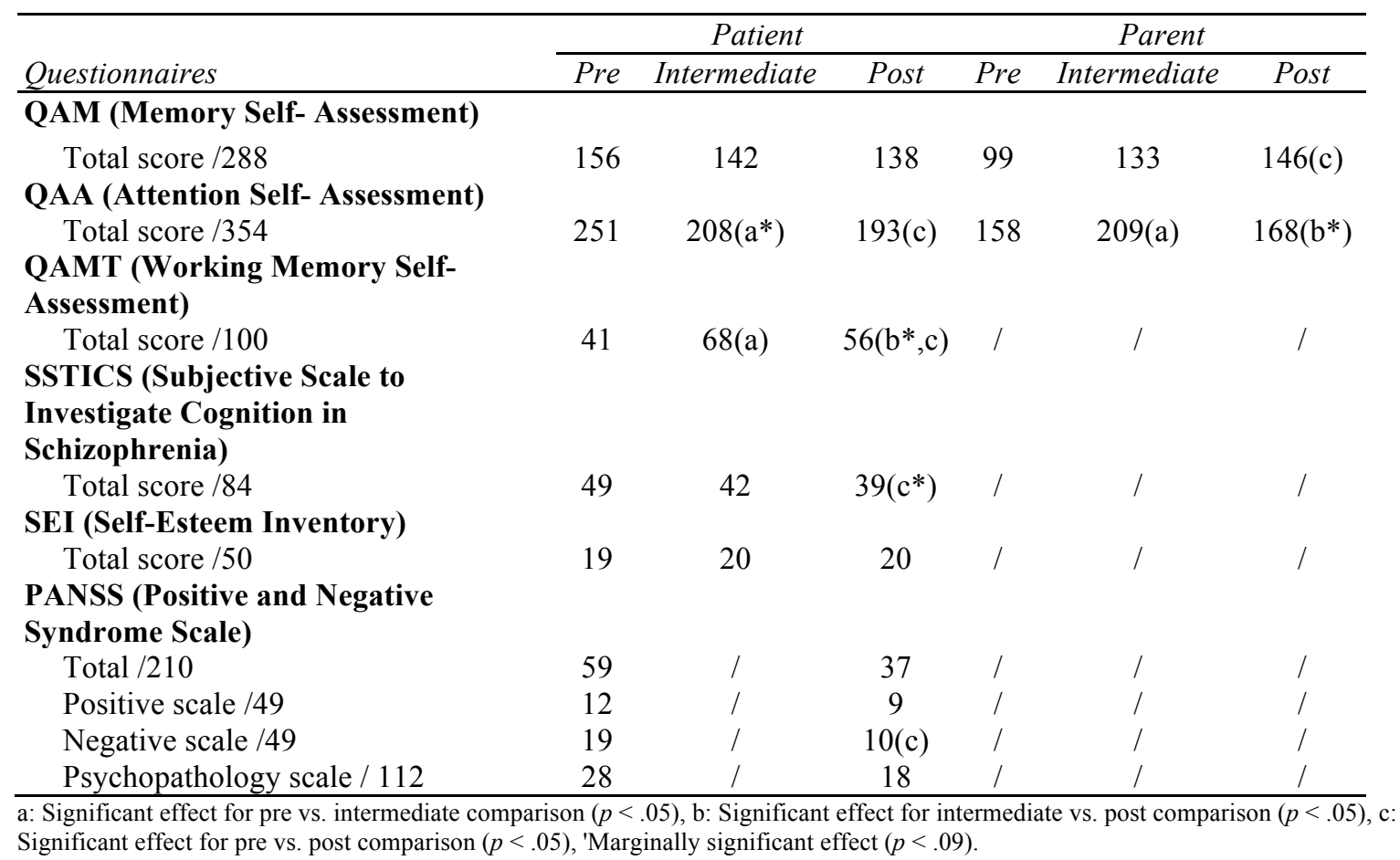

\section{Questionnaires}

The results of the questionnaires are presented in Table 5. Three comparisons for the questionnaires were carried out: (1) pre- versus intermediate rehabilitation (evaluating the effect of the cognitive sub-programme), (2) intermediate versus post-rehabilitation (evaluating the effect of the ecological sub-programme), and (3) preversus post-rehabilitation (evaluating the effect of the rehabilitation programme in its entirety).

The statistical methods included chi-square tests to compare the pairs of maximum score (\%) on questionnaires.

$Q A M$

The total score for complaints decreased progressively throughout the rehabilitation period, but the difference was not statistically significant for any of the comparisons: pre vs. intermediate, $\chi^{2}(1)=0.5 ; p=.48$, intermediate vs. post, $\chi^{2}(1)=0.02 ; p=.89$, and pre vs. post, $\chi^{2}(1)=0.72 ; p=.4$. However, cognitive complaints specifically related to working memory revealed a significant decrease in the pre vs. intermediate, $\chi^{2}(1)=7.12 ; p=.008$, and pre vs. post comparisons, $\chi^{2}(1)=10.38 ; p=.001$, but not in the intermediate vs. post comparisons, $\chi^{2}(1)=0.32$; $p=.57$.

Paradoxically, the evaluation completed by YN's mother suggested the opposite, even though she did say that she had observed an improvement in YN's memory functioning.

$Q A A$

For the pre vs. intermediate comparison, a marginally significant decrease in complaints was observed for the total score, $\chi^{2}(1)=3.16 ; p=.08$, but not for the working memory sub-scale, $\chi^{2}(1)=0.23 ; p=.63$. For the intermediate vs. post comparison, no difference was observed for the total score, $\chi^{2}(1)=0.33 ; p=.57$, but the complaints reported on the working memory sub-scale decreased, $\chi^{2}(1)=6.49 ; p=.01$. Finally, the pre vs. post comparison showed a significant decrease in the total score for complaints, $\chi^{2}(1)=5.49 ; p=.02$ and the score for working memory complaints, $\chi^{2}(1)=4.31 ; p=.04$. As assessed by YN's mother, complaints increased after the 
cognitive sub-programme but returned to their initial level after the ecological sub-programme.

$Q A M T$

A general increase in complaints reported on this scale was observed for the pre vs. intermediate comparison, $\chi^{2}(1)=14.7 ; p<.001$, and for the pre vs. post comparison, $\chi^{2}(1)=4.5 ; p=.03$. However, the intermediate vs. post comparison showed a marginally significant decrease, $\chi^{2}(1)=3.06 ; p=.08$.

\section{SSTICS}

A marginal decrease in complaints was observed only for the pre vs. post comparison, $\chi^{2}(1)=2.88 ; p=.09$, and essentially concerned attentional complaints. Moreover, the results revealed a negative association between scores on the SSTICS and the cognitive assessment. That is, improvements on the cognitive tests were associated with a reduction in subjective cognitive complaints.

\section{SEI}

All comparisons for scores on the SEI revealed that the cognitive rehabilitation had had no effect on self-esteem (pre vs. intermediate comparison, $\chi^{2}(1)=0.08, p=.77$; intermediate vs. post comparison, $\chi^{2}(1)=0 ; p=1$; pre vs. post comparison, $\chi^{2}(1)=0.08 ; p=.77$

\section{Psychiatric symptoms}

A significant decline was noted only on the PANSS negative sub-scale, $\chi^{2}(1)=8.68 ; p=.003$, after rehabilitation. Scores on the other PANSS sub-scales (positive, $\chi^{2}(1)=1.08 ; p=.3$, and psychopathology, $\chi^{2}(1)=$ $2.49 ; p=.11)$ and the total PANSS $\left(\chi^{2}(1)=2.69 ; p=.1\right)$ score showed a non-significant decrease.

\section{Qualitative self-assessment}

At the end of the cognitive rehabilitation programme, YN mentioned certain changes that had taken place. For example, he reported fewer difficulties following conversations, TV programmes and movies and reading newspapers. He also found that he was less fatigued and less distracted. Finally, he mentioned some more general changes that may be indirectly related to the cognitive rehabilitation programme. These changes concerned both the professional (e.g., he wanted to quit working in the accounting firm and start working in gardening, albeit with fewer hours) and the personal level (e.g., he expressed a wish to live on his own and become more autonomous).

\section{DISCUSSION}

The aim of this case study was to examine the specific impact that a cognitive rehabilitation programme targeting updating problems would have on a schizophrenia patient in terms of his cognitive functioning, functioning in daily life, psychiatric symptoms and self-esteem. Two types of updating exercises were given: cognitive and ecological. Furthermore, the patient was taught how to acquire cognitive strategies to alleviate the mental load of the central executive and then transfer these strategies to everyday situations. Multiple baseline measurements (cognitive, ecological, and non-target) were constructed to assess the programme's specificity and efficacy. In addition, several questionnaires were administered to assess the effect of the programme on subjective cognitive complaints in daily life, psychiatric symptoms and self-esteem.

Our study showed that the cognitive rehabilitation programme had a beneficial effect on the updating function of working memory in a schizophrenia patient, and that this beneficial effect transferred to some of the patient's daily life situations. After completion of the rehabilitation programme, neuropsychological assessment revealed improvements in YN's updating function. The beneficial effect of the rehabilitation programme was evidenced in the cognitive (3-back and size judgement) and ecological (scenarios analysis and simulations of real-life situations) baselines, both of which showed significant improvement. Moreover, this improvement cannot be attributed to spontaneous recovery, since performance on baseline measurements was stable, or declined, before rehabilitation.

YN also affirmed that certain changes had taken place in his daily life following the cognitive rehabilitation programme, as disclosed in response to open-ended questioning and self-assessment questionnaires. In particular, he reported having fewer difficulties following conversations, TV programmes and movies and reading newspapers. He also noticed that he was less fatigued and less distracted. Moreover, information provided to YN regarding the effects of anxiety and stress on working memory had allowed him to organise his daily life activities in an optimal manner. Regarding the results on the self-assessment questionnaires, an overall decrease in memory and attention complaints was observed after the rehabilitation process was completed. This suggests that $\mathrm{YN}$ was able to perceive his own cognitive improvement. However, while $\mathrm{YN}$ essentially reported complaints related to attentional difficulties in self-assessment questionnaires, the objective assessment of his 
cognitive functioning (neuropsychological testing) did not reveal any clear attentional difficulties, but rather, revealed memory deficits. This evidence of a discrepancy between subjective and objective evaluations of cognitive functioning is in line with the results obtained by Prouteau et al. (2004). Surprisingly, subjective complaints about working memory (based on the results of the QAMT) increased after the cognitive rehabilitation. Moreover, the evaluation completed by YN's mother also suggested an increase of complaints on the QAM (after the cognitive and ecological rehabilitation) and on the QAA (after the cognitive rehabilitation). These results are contradictory to what YN said during the intermediate assessment and the results of other questionnaires (working memory sub-scale on the QAM). This might be due to the fact that YN and his mother had become more aware of YN's working memory difficulties in daily life. Furthermore, they are not in accordance with a possible "likeability" effect from YN or his mother on the subjective rating scales, as if this were the case then the pattern of results would have revealed an important reduction of subjective cognitive complaints after cognitive rehabilitation, both as reported by the patient and his mother, and not an increase of such complaints.

The successive use of two sub-programmes deserves further comment. After the cognitive rehabilitation subprogramme, there was a significant improvement in YN's performance on one of the two cognitive tasks (3back). However, it is worth mentioning that the size judgement cognitive task revealed some improvement even though this was not statistically significant. After the ecological rehabilitation sub-programme, both ecological tasks (scenarios analysis and simulations of real-life situations) improved significantly. Although the results revealed that each sub-programme had a positive effect on the respective baseline measurements, they also showed that the improvement observed after the cognitive sub-programme was generalised to one of the ecological tasks (simulations of real-life situations). Indeed, since the cognitive sub-programme aimed to teach three cognitive strategies (repetition, mental visualisation and updating), the patient might have progressively acquired a metacognitive representation of these strategies which he could apply in the ecological situations. Improvement following the ecological sub-programme also had a beneficial effect on one of the cognitive tasks (3-back). These results emphasise the importance of including ecological exercises not only in order to improve targeted cognitive functions, but also so that their beneficial effects are transferred to daily life.

Although a number of executive functions were not directly rehabilitated in this cognitive rehabilitation programme, the results of the neuropsychological assessment revealed that certain non-target functions also improved: processing load of working memory, flexibility and planning. Interestingly, Reeder, Newton, Frangou, and Wykes (2004) have reported that various executive function tests in schizophrenia patients, including those assessing processing load (digit span), flexibility (verbal fluency), and planning (Six Elements Test), were all closely related to a working memory factor. In the present study, updating training had a beneficial effect on processing load. It is difficult to compare these results with the only study (Duval et al., 2008) that has applied the same cognitive rehabilitation programme to a patient who had working memory deficits after a surgical operation for a cerebral tumour (ganglioglioma II), since this study observed a ceiling effect for the updating baselines (2-back task). However, they did observe that processing load training had a beneficial effect on dual-task monitoring. Both of these results suggest that the dual-task monitoring and updating sub-processes seem to be related to processing load. Concerning the improvements observed in the other executive functions, namely flexibility and planning, this is in line with the Duval et al. (2008) findings. This result indicates that either the tasks are not pure or that these processes (updating, flexibility and planning) are functionally inter-related. With regard to findings of improved flexibility, Miyake et al. (2000) have shown that the updating and flexibility functions, although dissociable, are also moderately correlated. This might explain the transfer of the beneficial effects of the updating function to flexibility. As for the improvement in planning functions, Duval et al. (2008) suggest that an increase in processing load capacity (e.g., as a result of updating improvement, as was observed in the present study) might explain these beneficial effects: the patient now has more cognitive resources available to plan his actions. The improvement in planning might also be explained by the updating improvement because the Six Elements Test (which assesses planning) requires the patient to keep the test instructions in mind throughout the task, but also to update memory for the tasks just carried out. Moreover, the non-target baselines (verbal episodic memory task) showed a significant improvement following the entire rehabilitation programme. This may be related to YN's use of the dual coding strategies (verbal and visual) that he learned in the cognitive sub-programme.

The absence of any improvements (based on neuropsychological assessment) in cognitive functions related to working memory, which were within the norms before the treatment and were not directly rehabilitated, demonstrates the specificity of the cognitive rehabilitation programme used in our study. In particular, no improvement was observed for the dual-task monitoring function. This is in accordance with Miyake et al. (2000), who have shown that dual-task monitoring is the only complex executive task that is not clearly related to the three target executive functions (flexibility, inhibition, and updating). Moreover, no change was observed for other cognitive functions: short-term memory storage, inhibition, divided attention and sustained attention. Similarly, these functions (except sustained attention, which was not assessed) did not improve in the Duval et 
al. (2008) study. Thus, a general practice effect of the rehabilitation programme cannot explain our results. Verbal episodic memory, which was impaired before the rehabilitation programme, remained impaired afterwards. However, the results based on the non-target baselines (verbal episodic memory task) did improve to some extent. Therefore, it is difficult to draw any conclusions regarding the absence of a beneficial effect of the rehabilitation programme on verbal episodic memory. Since working memory and episodic memory are closely related on a theoretical level (Baddeley, 2000; Ranganath, Cohen, \& Brozinsky, 2005; Van der Linden, Meulemans, Marczewski, \& Colette, 2000), this strongly suggests that rehabilitating working memory deficits will also have a beneficial impact on episodic memory functioning.

YN's psychiatric symptomatology, levels of anxiety and depression (which were very high at the beginning of the rehabilitation) diminished noticeably. Moreover, a significant decrease in negative symptoms (social withdrawal and apathy) was observed after the entire cognitive rehabilitation programme. Several earlier studies have also found a relationship between working memory deficits and negative symptoms (e.g., Reeder et al., 2004; Twamley, Palmer, Jeste, Taylor, \& Heaton, 2006) and others have observed the beneficial effect of a cognitive rehabilitation programme on negative symptoms (e.g., Cochet et al., 2006; Medalia, Dorn, \& WatrasGans, 2000; Wykes, Reeder, Corner, Williams, \& Everitt, 1999; Wykes et al., 2003). Nevertheless, the mechanisms underlying the beneficial effects of a cognitive rehabilitation programme on (negative) symptom severity have not been directly examined in the scientific literature, although Greenwood, Landau, and Wykes (2005) provided an interesting account of the possible mechanisms involved in interactions between negative symptoms and cognition in predicting community functioning. This issue merits to be examined more directly and in more detail in future studies.

The cognitive rehabilitation programme did not have an effect on YN's self-esteem. This is not in accordance with the only two studies (Wykes et al., 1999, 2003, two studies that included the same participants) that had previously examined this question, which found that a cognitive rehabilitation programme had a positive effect on self-esteem. Wykes et al. (1999) note that this observed beneficial effect may be due, at least in part, to the fact that patients were able to perceive their increased performance thanks to the use of such techniques as errorless learning. It is important to note that Wykes et al. (2003) observed that the improvement in self-esteem at the post-treatment assessment had disappeared at the follow-up ( 6 months post-therapy). In our study, a more complete self-esteem measure was used (consisting of 50 items); furthermore, it evaluates four different domains of self-esteem (general, social, familial, and professional), unlike previous studies that used a shorter measure of self-esteem (i.e., the Rosenberg Self Esteem Schedule; 10 items; Rosenberg, 1965), and where, moreover, only a total score was used. Nevertheless, the results of our study did not reveal any improvements in self-esteem. Perhaps cognitive rehabilitation must occur over longer periods of time in order to observe such improvements.

The present study programme has a number of limitations. First, while YN used the subvocal repetition and serial work strategies in his daily life, he found it difficult to apply the visualisation strategy in the ecological exercises. This may be because the number of rehabilitation sessions with the ecological exercises was not sufficient for an adequate transfer to daily life of all the organisational strategies he had learned. Moreover, the durability of the effect of the cognitive rehabilitation programme was not examined. Second, because of clinical constraints, the same person carried out the evaluations and administered the cognitive rehabilitation programme, and so we did not use "blind evaluation" by a neutral tester. We could therefore not completely protect against a Rosenthal effect (i.e., that one's beliefs, biases and expectations can have an influence on the phenomenon under investigation). However, the evaluation of the efficacy of the cognitive remediation programme was based on objective measures (i.e., baseline measurements and neuropsychological testing), which contain clear scoring criteria. Finally, concerning the scenarios analysis measures, since scores only ranged between 0 and 3 , the statistical reliability of these results may be questionable. In order to assess more accurately the effects of this cognitive rehabilitation programme, future studies should consider including more difficult tasks (to increase score variance) and increasing the number of items or stimuli in order to improve the power analysis.

\section{REFERENCES}

Alptekin, K., Akvardar, Y., Akdede, B. B. K., Dumlu, K., Isik, D., Pirincci, F. et al. (2005). Is quality of life associated with cognitive impairment in schizophrenia? Progress in Neuro-Psychopharmacology and Biological Psychiatry, 29, 239-244.

American Psychiatric Association (1994). Diagnostic and statistical manual of mental disorders, (4th ed.). Washington, DC: American Psychiatric Association.

Baddeley, A. D. (1986). Working Memory. Oxford: Clarendon Press.

Baddeley, A. D. (1992). Is working memory working? Quarterly Journal of Experimental Psychology, 44A, 1-31.

Baddeley, A. D. (2000). The episodic buffer: A new component of working memory? Trends in Cognitive Sciences, 4, 417-423.

Baddeley, A. D., \& Wilson, B. A. (2002). Prose recall and amnesia: Implications for the structure of working memory. Neuropsychologia, 40, 1737-1743.

Bagner, D. M., Melinder, M. R. D., \& Barch, D. M. (2003). Language comprehension andworking memory language comprehension and 
working memory deficits in patients with schizophrenia. Schizophrenia Research, 60, 299-309.

Barch, D. M., Carter, C. S., Braver, T. S., Sabb, F. W., MacDonald III, A., Noll, D. C. et al. (2001). Selective deficits in prefrontal cortex function in medication-naive patients with schizophrenia. Archives of General Psychiatry, 58, 280-288.

Belleville, S., Rouleau, N, \& Caza, N. (1988). Effect of normal aging on the manipulation of information in working memory. Memory and Cognition, 26, 572-583

Callicott, J. H., Bertolino, A., Mattay, V. S., Langheim, F. J. P., Dyun, J., Coppola, R. et al. (2000). Physiological dysfunction of the dorsolateral prefrontal cortex in schizophrenia revisited. Cerebral Cortex, 10, 1078-1092.

Carter, C. S., Perlstein, W., Ganguli, R., Brar, J., Mintun, M., \& Cohen, J. D. (1998). Functional hypofrontality and working memory dysfunction in schizophrenia. American Journal of Psychiatry, 155, 1285-1287.

Carter, C., Robertson, L., Nordahl, T., Chaderjian, M., Kraft, L., \& O'Shora-Celaya, L. (1996). Spatial working memory deficit and their relationship to negative symptoms in unmedicated schizophrenia patients. Biological Psychiatry, 40, 930-932.

Chan, R. C. K., Chen, E. Y. H., \& Law, C. W. (2006). Specific executive dysfunction in patients with first-episode medication-naive schizophrenia. Schizophrenia Research, 82, 51-64.

Cochet, A., Saoud, M., Gabriele, S., Broallier, V., El Asmar, C, Daléry, J. et al. (2006). Impact de la remédiation cognitive dans la schizophrenie sur les stratégies de résolution de problèmes et l'autonomie sociale: Utilisation du logiciel REHACOM. L'Encéphale, 32, 189195.

Cohen, J. (1988). Statistical Power Analysis for the Behavioral Sciences (2nd Ed.) Hillsdale, NJ: Lawrence Erlbaum Associates. Conklin, H. M., Curtis, C. E., Katsanis, J., \& Iacono, W. G. (2000). Verbal working memory impairment in schizophrenia patients and their first-degree relatives: Evidence from the Digit Span task. American Journal of Psychiatry, 157, 275-277.

Coopersmith, S. (1981). Self-Esteem Inventories. Palo Alto, CA: Consulting Psychologists. Coopersmith, S. (1984). Inventaire D'estime de Soi (SEI). Traduction Française. Paris: Les Editions du Centre de Psychologie Appliquee.

Cornblatt, B. A., Risch, N, Faris, J., Friedman, G, \& Erlenmeyer-Kimling, D. (2004). Continuous Performance Test, identical pairs version (CPT-IP): I. New findings about sustained attention in normal families. Psychiatry Research, 26, 223-238.

Coyette, F., Arno, P., Leclerq, M., Seron, X., Van der Linden, M., \& Grégoire, J. (1999). Questionnaire d'Auto-évaluation de l'Attention (QAA). Unpublished document, Centre de Revalidation Neuropsychologique des Cliniques Universitaires Saint-Luc, Brussels, Belgium.

Daban, C., Amado, I., Bourdel, M.-C, Loo, H., Olié, J.-P., Poirier, M.-P. et al. (2005). Cognitive dysfunctions in medicated and unmedicated patients with recent-onset schizophrenia. Journal of Psychiatry Research, 39, 391-398.

Duval, J., \& Coyette, F. (2005). Programme de Revalidation de l'Administrateur Central de la Mémoire de Travail. Unpublished document. Louvain: Centre de revalidation neuropsychologique, Cliniques Universitaires Saint-Luc.

Duval, J., Coyette, F., \& Seron, X. (2008). Rehabilitation of the central executive component of working memory: A reorganisation approach applied to a single case. Neuropsychological Rehabilitation.(in press).

Galletly, C. A., MacFarlane, A. C., \& Clark, C. R. (2007). Impaired updating of working memory in schizophrenia. International Journal of Psychophysiology, 63, 265-274.

Garnier, C, Enot-Joyeux, F., Jokic, C, Le Thiec, F., Desgranges, B., \& Eustache, F. (1998). Une évaluation des fonctions exécutives chez les traumatisés craniens: L'adaptation du test des six éléments. Revue de Neuropsychologie, 8, 385-414.

Goldberg, T. E., Egan, M. F., Gscheidle, T., Coppola, R., Weickert, T., Kolachana, B. S. et al. (2003). Executive subprocesses in working memory: Relationship to catechol-O-methyltransferase vall58Met genotype and schizophrenia. Archives of General Psychiatry, 60, 889-896.

Goldstein, G., \& Shemansky, W. J. (1995). Influences on cognitive heterogeneity in schizophrenia. Schizophrenia Research, 18, 59-69.

Green, M. F. (1996). What are the functional consequences of neurocognitive deficits in schizophrenia? American Journal of Psychiatry, $153,321-330$

Green, M. F., Kern, R. S., Braff, D. L., \& Mintz, J. (2000). Neurocognitive deficits and functional outcome in schizophrenia: Are we measuring the "right stuff? Schizophrenia Bulletin, 26, 119-136.

Greenwood, K. E., Landau, S., \& Wykes, T. (2005). Negative symptoms and specific cognitive impairments as combined targets for improved functional outcome within cognitive remediation therapy. Schizophrenia Bulletin, 31, 910-921.

Gur, R. E., Calkins, M. E., Gur, R. C., Horan, W. P., Nuechterlein, K. H., Seidman, L. J. et al. (2007). The consortium on the genetics of schizophrenia: Neurocognitive endophenotypes. Schizophrenia Bulletin, 33, 49-68.

Hiernaux, A., \& Demoulin, V. (1999). Questionnaire d'Auto-évaluation de la Mémoire de Travail (QAMT). Unpublished document. Liège: Service de Neuropsychologie des Cliniques Universitaires du Sart-Tilman.

Hofer, A., Baumgartner, S., Bodner, T., Edlinger, M., Hummer, M., Kemmler, G. et al. (2005). Patient outcomes in schizophrenia II: The impact of cognition. European Psychiatry, 20, 395-402.

Joyce, E. M., Hutton, S. B., Mutsatsa, S. H., \& Barnes, T. R. E. (2005). Cognitive heterogeneity in first-episode schizophrenia. British Journal of Psychiatry, 187, 516-522.

Joyce, E. M., \& Roiser, J. P. (2007). Cognitive heterogeneity in schizophrenia. Current Opinion in Psychiatry, 20, $268-272$.

Kay, S. R., Opler, L. A., \& Fiszbein, A. (1986). Positive and Negative Syndrome Scale (PANSS), Rating Manual. New York: Albert Einstein College, SF Medicine, Department of Psychiatry.

Krieger, S., Lis, S., Cetin, T., Gallhofer, B., \& Meyer-Lindenberg, A. (2005). Executive function and cognitive subprocesses in first-episode, 
drug-naive schizophrenia: An analysis of n-back performance. American Journal of Psychiatry, 162, 1206-1208.

Lee, J., \& Park, S. (2005). Working memory impairments in schizophrenia: A meta-analysis. Journal of Abnormal Psychology, 114, 599611 .

Lépine, J. P., Piron, J. J., \& Chapatot, E. (1989). Factor analysis of the PANSS in schizophrenia patients. In C. N. Stefanis, C. R. Soltados, \& A. D. Rabavilas (Eds.), Psychiatry Today: Accomplishments and Promises. Amsterdam: Experta Medica.

Mackinnon, A., \& Mulligan, R. (2005). Estimation de l'intelligence prémorbide chez les francophones. L'Encéphale, $31,31-43$.

Marsh, R., Alexander, G. M., Packard, M. G, Zhu, H., \& Peterson, B. S. (2005). Perceptual-motor skill learning in Gilles de la Tourette syndrome: Evidence for multiple procedural learning and memory systems. Neuropsychologia, 43, 1456-1465.

McGurk, S. R., Twamley, E. W., Sitzer, D. I., McHugo, G. J., \& Mueser, K. T. (2007). A metaanalysis of cognitive remediation in schizophrenia. American Journal of Psychiatry, 164, 1791-1802.

Medalia, A., Dorn, H., \& Watras-Gans, S. (2000). Treating problem-solving deficits on an acute care psychiatric inpatient unit. Psychiatry Research, 97, 79-88.

Meulemans, T., Coyette, F., \& Van der Linden, M. (in preparation). Adaptation et validation du test informatise de Brown-Peterson.

Mitropoulou, V., Harvey, P. D., Zegarelli, G, New, A. S., Silverman, J. M., \& Siever, L. J. (2005). Neuropsychological performance in schizotypal personality disorder: Importance of working memory. American Journal of Psychiatry, 162, 1896-1903.

Miyake, A., Friedman, N. P., Emerson, M. J., Witzki, A. H., Howerter, A., \& Wager, T. D. (2000). The unity and diversity of executive functions and their contributions to complex "frontal lobe" tasks: A latent variable analysis. Cognitive Psychology, 41, 49-100.

Myles-Worsley, M., \& Park, S. (2002). Spatial working memory deficits in schizophrenia patients and their first degree relatives from Palau, Micronesia. American Journal of Medical Genetics, 114, 609-615.

Nelson, H. E. (1982). National Adult Reading Test. Windsor, UK: NFER-Nelson.

Palladino, P., Cornoldi, C., De Beni, R., \& Pazzaglia, F. (2001). Working memory and updating processes in reading comprehension. Memory and Cognition, 29, 344-354.

Park, S., Holzman, P. S., \& Lenzenweger, M. F. (1995). Individual differences in spatial working memory in relation to schizotypy. Journal of Abnormal Psychology, 104, 355-363.

Park, S., \& McTigue, K. (1997). Working memory and the syndromes of schizotypal personality. Schizophrenia Research, 26, 213-220.

Perlstein, W. M., Dixit, N. K., Carter, C. S., Noll, D. C, \& Cohen, J. D. (2003). Prefrontal cortex dysfunction mediates deficits in working memory and prepotent responding in schizophrenia. Society of Biological Psychiatry, 53, 25-38.

Prouteau, A., Verdoux, H., Briand, C., Lesage, A., Lalonde, P., Nicole, L. et al. (2004). Self-assessed cognitive dysfunction and objective performance in outpatients with schizophrenia participating in a rehabilitation programme. Schizophrenia Research, 69, 85-91.

Ranganath, C., Cohen, M. X., \& Brozinsky, C. J. (2005). Working memory maintenance contributes to long-term memory formation: Neutral and behavioral evidence. Journal of Cognitive Neuroscience, 17, 994-1010.

Reeder, C., Newton, E., Frangou, S., \& Wykes, T. (2004). Which executive skills should we target to affect social functioning and symptom change? A study of a cognitive remediation therapy programme. Schizophrenia Bulletin, 30, 87-100.

Reitan, R. M. (1958). Validity of the Trail Making Test as an indication of organic brain damage. Perceptual Motor Skills, 8, 271-276.

Rosenberg, M. (1965). Society and the Adolescent Self Image. Princeton, NJ: Princeton University Press.

Seaton, B. E., Goldstein, G, \& Allen, D. N. (2001). Sources of heterogeneity in schizophrenia: The role of neuropsychological functioning. Neuropsychology Review, 11, 45-67.

Seron, X., \& Van der Linden, M. (2000). Objectifs et strategies de la revalidation neuropsychologique. In X. Seron \& M. Van der Linden (Eds.), Traité de Neuropsychologie Clinique, Tome II (pp. 9-16). Marseille: Solal.

Shallice, T., \& Burgess, P. W (1991). Deficits in strategy application following frontal lobe damage in humans. Brain, 114, 727-741.

Shallice, T., Burgess, P. W., \& C. D. Frith (1991). Can the neuropsychological case-study approach be applied to schizophrenia? Psychological Medicine, 21, 621-673.

Silver, H., \& Feldman, P. (2005). Evidence for sustained attention and working memory in schizophrenia sharing a common mechanism. Journal of Neuropsychiatry and Clinical Neurosciences, 17, 391-398.

Silver, H., Feldman, P., Bilker, W., \& Gur, R. C. (2003). Working memory deficit as a core neuropsychological dysfunction in schizophrenia. American Journal of Psychiatry, 160, 1809-1816.

Stip, E., Caron, J., Renaud, S., Pampoulova, T., \& Lecomte, Y. (2003). Exploring cognitive complaints in schizophrenia: The subjective scale to investigate cognition in schizophrenia. Comprehensive Psychiatry, 44, 331-340.

Takahashi, H., Iwase, M., Nakahachi, T., Sekiyama, R., Tabushi, K., Kajimoto, O. et al. (2005). Spatial working memory deficit correlates with disorganization symptoms and social functioning in schizophrenia. Psychiatry and Clinical Neurosciences, 59, 453-460.

Tallent, K. A., \& Gooding, D. C. (1999). Working memory and Wisconsin Card Sorting Test performance in schizotypic individuals: A replication and extension. Psychiatry Research, 89, 161-170.

Twamley, E. W., Palmer, B. W., Jeste, D. V., Taylor, M. J., \& Heaton, R. K. (2006). Transient and executive function working memory in schizophrenia. Schizophrenia Research, 87, 185-190. 
Van der Linden, M., Meulemans, T., Marczewski, P., \& Colette, F. (2000). The relationships between episodic memory, working memory, and executive functions: The contribution of the prefrontal cortex. Psychologica Belgica, 40, 275-297.

Van der Linden, M., Wyns, C, Coyette, F., von Frenckell, R., \& Seron, X. (1989). Questionnaire d'Auto-évaluation de la Mémoire (QAM). Brussels: Editest.

Van der Linden, M., Adam, S., Agniel, A., Baisset-Mouly, C., Bardet, F., Coyette, F., et al. (2004). L'évaluation des Troubles de la Mémoire: Présentation de Quatre Tests de Mémoire Episodique (avec leur étalonnage). Marseille: Solal.

Wechsler, D. (2000). WAIS-III: Echelle d'Intelligence de Wechsler pour Adultes (3rd ed.). Paris: Les éditions du Centre de Psychologie.

Wechsler, D. (2001). MEM-III: Manuel de l'Echelle Clinique de Mémoire (3rd ed.). Paris: Les éditions du Centre de Psychologie.

Wilson, B. A., Alderman, N., Burgess, P., Emslie, H., \& Evans, J. J. (1996). Behavioral Assessment of the Dysexecutive Syndrome (BADS). Bury St. Edmunds, UK: Thames Valley Test Company.

World Health Organization (1980). International Classification of Impairments, Disabilities and Handicaps. Geneva: Author.

Wykes, T., Reeder, C, Corner, J., Williams, C, \& Everitt, B. (1999). The effects of neurocognitive remediation on executive processing in patients with schizophrenia. Schizophrenia Bulletin, 25,291-307.

Wykes, T., Reeder, C, Williams, C, Corner, J., Rice, C, \& Everitt, B. (2003). Are the effects of cognitive remediation therapy (CRT) durable? Results from an exploratory trial in schizophrenia. Schizophrenia Research, 61, 163-174.

Zimmerman, P., \& Fimm, B. (1994). Test for Attentional Performance (TAP). Herzogenrath, Germany: PsyTest. 